\title{
COVID-19 and social distancing measures in Queensland, Australia, are associated with short-term decreases in recorded violent crime
}

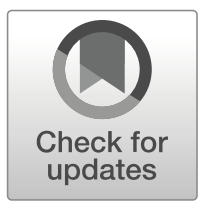

\author{
Jason L. Payne ${ }^{1}$ (D) Anthony Morgan ${ }^{2}$ - Alex R. Piquero ${ }^{3,4}$ \\ Published online: 29 July 2020 \\ (C) Springer Nature B.V. 2020
}

\begin{abstract}
Objectives The objective of this study is to test whether recorded rates of violent crime declined in the context of social distancing regulations in Queensland, Australia.

Methods ARIMA modeling was used to compute 6-month-ahead forecasts of rates for common assault, serious assault, sexual offenses, and breaches of domestic violence orders. These forecasts (and their 95\% confidence intervals) are compared to the observed data for March and April 2020.

Results By the end of April, 2020, rates of common, serious, and sexual assault had declined to their lowest level in a number of years. For serious assault and sexual assault, the decline was beyond statistical expectations. The rate at which domestic violence orders were breached remained unchanged.

Conclusions Social distancing regulations are temporally correlated with reductions in some violent crimes. Social distancing is likely to have significantly limited interpersonal interaction, especially in locations and at times when violence is usually prevalent.
\end{abstract}

Keywords COVID-19 $\cdot$ Violence $\cdot$ Queensland $\cdot$ Social distancing · ARIMA

Jason L. Payne

jason.payne@anu.edu.au

1 Australian National University, Canberra, Australia

2 Australian Institute of Criminology, Canberra, Australia

3 University of Miami, Coral Gables, FL, USA

4 Monash University, Melbourne, Australia 


\section{Introduction}

The World Health Organization (WHO) declared the novel coronavirus disease 2019 (COVID-19) outbreak, caused by severe acute respiratory syndrome coronavirus-2 (SARS-CoV-2), to be a public health emergency of international concern on 30 January 2020 (World Health Organization 2020). Since this time, countries around the world have been affected in unprecedented ways. The number of infections has risen quickly, as has the number of deaths attributed to the virus.

Following the first diagnosed case in late 2019, there have been more than 13 million confirmed cases of COVID-19 and half a million deaths worldwide. An important focus has been on the capacity of the health system in each country to respond to the pandemic. The early experience of China, followed by countries such as Italy, Iran, and more recently the UK and USA, where health systems have quickly become overwhelmed and struggled to cope with the demand from large numbers of infected patients, has motivated countries to take drastic action and implement a wide range of proactive and reactive measures to limit the spread of COVID-19.

Collectively referred to as "containment measures," these strategies are designed to limit community transmission between individuals. There is, unsurprisingly, a great deal of variation in the ways in which different countries have approached the pandemic, and the types of containment measures they have employed. Despite these differences, each jurisdiction's response has involved some combination of travel restrictions and border controls, quarantine requirements, social isolation and distancing requirements, and the large-scale closure of various services, business, and educational facilities. While the primary concern of government has been to minimize the health impacts of COVID-19, attention has also turned to the other effects of the pandemic. Significant societal and economic impacts have raised questions about potential increases in organized crime (Global Initiative Against Transnational Organized Crime 2020), cybercrime (Europol 2020), and violent crime (Eisner and Nivette 2020), particularly domestic violence (Fitz-Gibbon and Meyer 2020; van Gelder et al. 2020). Conversely, reductions in opportunistic, property crimes have been anticipated (Farrell and Tilley 2020). The impact of COVID-19 on law enforcement (Lum et al. 2020), courts (Rossner and Tait 2020), and correctional systems (Kinner et al. 2020) have also been the subject of speculation and analysis. Here, the focus has been primarily on the emerging health risks and the impact of containment measures on how these agencies and systems operate.

Particular attention has focused on the need for empirical research into the impact of COVID-19 and associated containment measures on violent crime (Eisner and Nivette 2020; Peterman et al. 2020). Changes in the routine activities of individuals, limited social interaction, the potential strain on relationships, fear and anxiety resulting from isolation, and the financial stress of job losses and reduced incomes each have the potential to influence violent crime in different ways. Understanding these impacts is important to inform how to respond, particularly as the pandemic and containment measures are likely to persist for some time yet. 
In this study, we use officially recorded police data from Queensland, Australia, to look for early signs that violent crime has changed in the context of the COVID-19 pandemic. In an international context, Australia is a unique site of analysis because the rapid introduction of strong social distancing regulations has coincided with the transition to winter - a time when seasonal crime rates are expected to fall. Without accounting for these seasonal effects, there is a risk that any observed short-term decline in crime may be overstated or incorrectly attributed as a consequence of COVID-19. In this study, we examine officially recorded violent crime rates for the month of March and April 2020. We conduct this analysis in Queensland because it was the first state or territory in Australia to declare a public health emergency on January 29, 2020. It is also the first jurisdiction to provide open access to up-to-date data.

\section{What restrictions have been introduced in Australia?}

Compared with other countries, the infection rate in Australia has remained relatively low. The first Australian case was recorded in January; however, the number of new cases increased rapidly during March (Fig. 1). There have been more than 7700 confirmed cases recorded in Australia (June 30) and more than 100 people have died as a result of the disease (Australian Government Department of Health 2020). Most confirmed cases acquired their infection during overseas travel, or via contact with someone who had travelled overseas, and onboard cruise ships (Australian Government Department of Health 2020).

Importantly, as a federated nation, responsibility for implementing containment measures is shared between the federal and state and territory governments, while

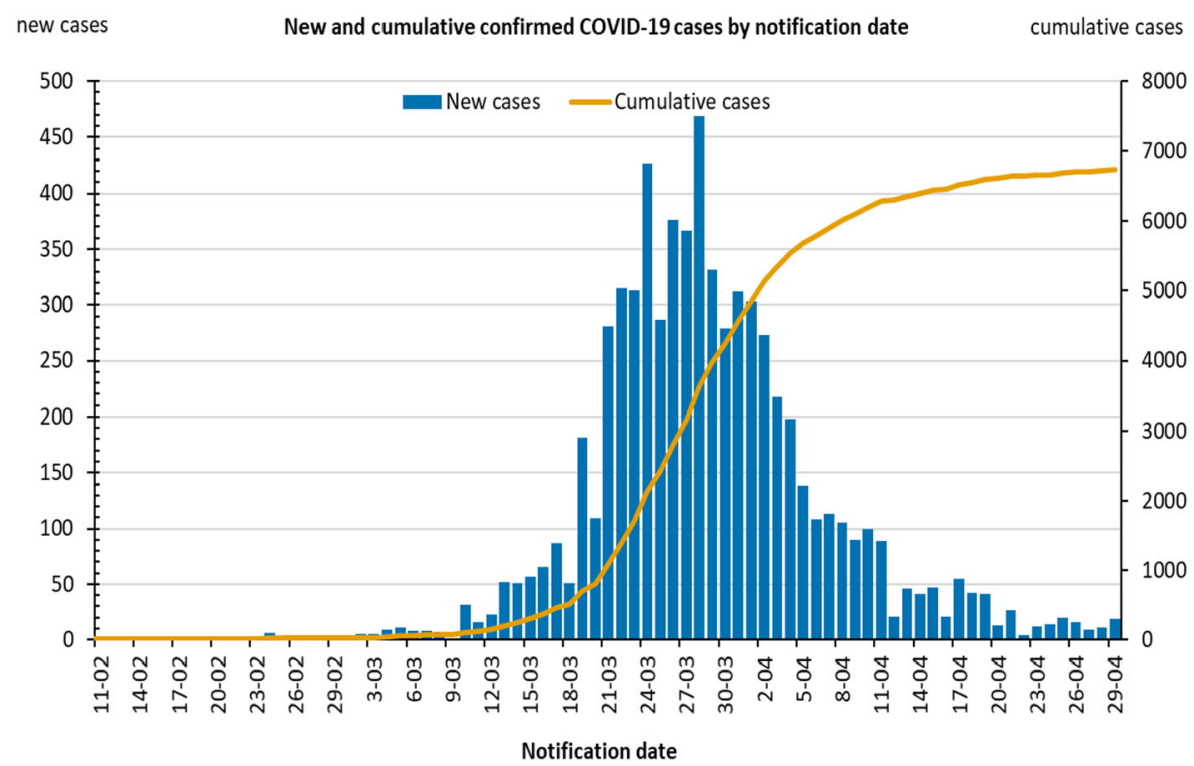

Fig. 1 New and cumulative confirmed COVID-19 cases by notification date. Source: Australian Government Department of Health, 2020b 
states and territories are able to choose how to enforce them. Although there has been a strong emphasis on a consistent national approach, there has also been variation in some of the measures employed in each jurisdiction. This has included strategies such as border controls and school closures.

Containment measures have been introduced incrementally (see Ting and Palmer 2020 for a detailed timeline). In terms of a national response, the entry of foreign nationals from mainland China was banned on February 1, before incremental travel bans on Iran, South Korea, and Italy in early March. This was followed by self-isolation requirements on all travelers arriving in Australia introduced on March 16. Large, non-essential, and organized public gatherings of more than 500 people were also restricted from this date, as were indoor gatherings of more than 100 people. At the same time, social distancing requirements were introduced, which required individuals to maintain a distance of $1.5 \mathrm{~m}$ (almost $5 \mathrm{ft}$ ) from one another. The Biosecurity (Human Biosecurity Emergency) (Human Coronavirus with Pandemic Potential) Declaration 2020 was announced on March 18, followed by a further announcement that Australian borders were closed to all non-Australian citizens and non-residents effective March 20. The following day, the requirement that there be $4 \mathrm{~m}^{2}$ per person in any enclosed space was introduced. On the 22nd of March, the Prime Minister announced large-scale closures of take-away liquor outlets, licensed premises, restaurants and cafes (except for takeaway food), entertainment venues, and places of worship, which took effect the following day. Further restrictions were imposed on a range of other venues, including indoor and outdoor markets, on March 26, while limits were placed on the number of people who are allowed to attend weddings and funerals. Public gatherings were limited to two people (non-family members) from March 30, and Australians were advised that they were only allowed to leave home for essential shopping, medical needs, exercise, or for work or education.

Queensland became the first Australian state or territory to declare a public health emergency under the Public Health Act 2005 on January 29, 2020, providing the Chief Health Officer with broad powers to make directions regarding the types of restrictions that may be imposed to limit the transmission of COVID-19. Since the non-essential business, activity, and undertaking closure direction was first released on March 23, a series of revisions have been made in line with national requirements, imposing further limits on which venues and businesses may continue to operate. School closures came into effect on March 30, remaining open to the children of essential service workers. Queensland borders were closed effective March 26, with entry limited to Queensland residents, residents of border communities undertaking essential activities, and other exempt persons. Non-residents were initially required to self-isolate for 14 days after crossing the border; however, as of early April, restrictions were tightened further and only Queensland residents could cross the border. These restrictions are enforceable by law.

\section{Why is violent crime likely to be impacted by COVID-19?}

Broadly speaking, there are several mechanisms through which the COVID-19 containment measures are likely to influence violence. We limit our discussion here to the most likely short-term situational effects that are best explained by 
routine activities theory (Cohen and Felson 1979) and the short-to-longer-term financial and emotional pressure (General Strain Theory, Agnew 1992) that might spur a range of negative emotions which, in turn, manifest as violence as the pandemic progresses.

\section{Routine activities}

The first, and most obvious of these mechanisms, is the impact on the routine activities of individuals. Routine activities play an important role in understanding when and where crime is more likely to occur. According to Cohen and Felson (1979), crime occurs when there is a convergence of three critical elements - a motivated offender, a suitable target and the absence of a capable guardian. Crime is more common in places where these three things converge on a regular basis. Crime pattern theory combines aspects of the routine activity approach and other environmental criminological theories and focuses on how offenders may come across opportunities for crime in the course of their everyday lives (Brantingham and Brantingham 1993). Brantingham and Brantingham (1995) describe crime as occurring when the activity spaces of offenders - which concentrate around the places they visit most frequently-intersect with the activity spaces of a target, precipitated by some triggering event. Obviously, major disruptions of these routine activities may have a significant impact on when, and where, we might expect crime to occur. Containment measures are likely to mean that much less time is spent interacting with other people in public settings and much more time spent at home.

When asked, adult Australians have reported a high degree of compliance with recommended social distancing practices, including keeping distance between people, avoiding public spaces, and avoiding large gatherings (Australian Bureau of Statistics 2020c). Google's (Google 2020) mobility data highlights how much peoples' movement and time spent in public and private spaces has changed as a result of the containment measures. Location data reported by Google on community mobility has tracked how often and for how long people travel to different location types, compared with a baseline value (the median value for the same day of the week in January and early February). Figure 2 shows these changes over time and demonstrates that there have been significant reductions in visits to public spaces, including parks (down $43 \%$ as of April 30), retail and recreation premises (down 39\%), workplaces (down 34\%), and transit stations (down 60\%). Not surprisingly, the time spent in residential locations has increased by $18 \%$, which may help to increase the opportunity for interpersonal violence. These changes took effect in late March and were sustained for most of the month of April as it was not until the beginning of May that these restrictions started to be loosened (Australian Broadcasting Corporation 2020a).

Figure 3 describes the trend as of the end of April for Australia, overall, and for Queensland and shows that the trends observed nationally were not as pronounced in Queensland. Nevertheless, similar trends in mobility were observed in Queensland in the second half of March, and these changes were sustained until the end of April. That significant changes in mobility were observed in March, seemingly in advance of the introduction of major restrictions, indicating that people changed 


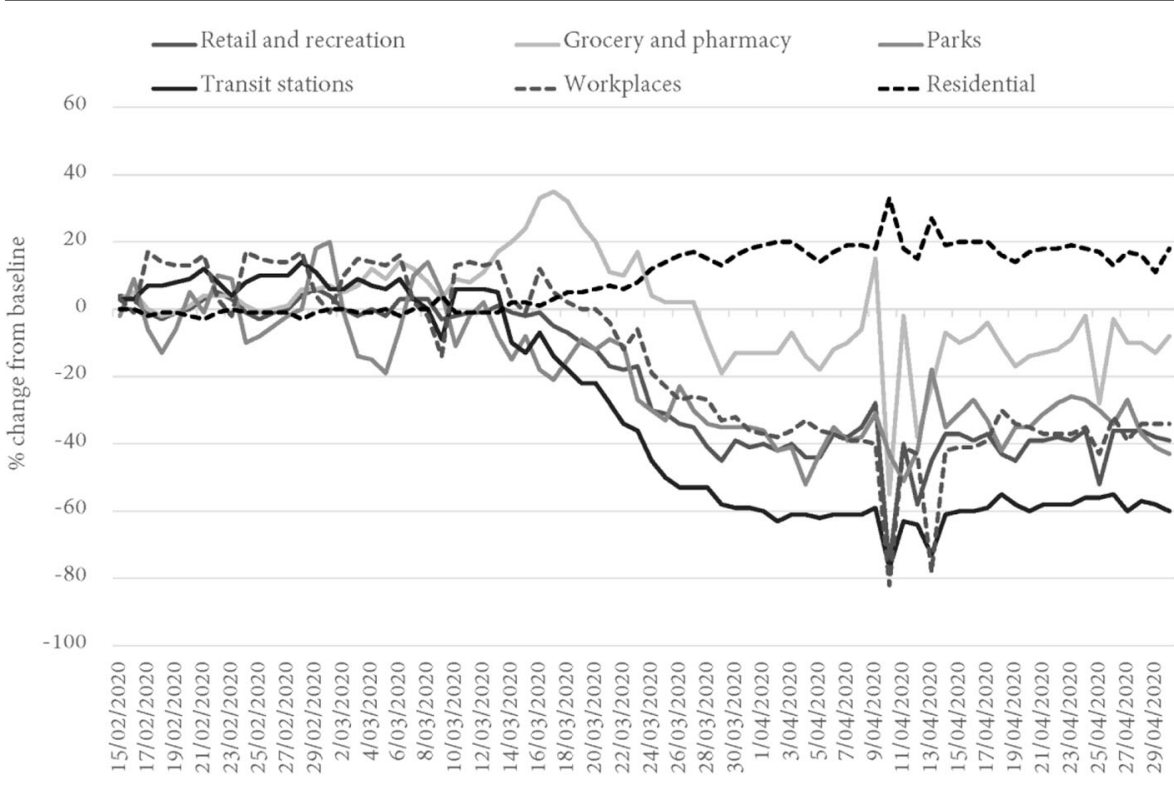

Fig. 2 Changes in mobility over time, Australia, 15 February-30 April. Source: Google COVID-19 Community Mobility Report

their behavior in response to the perceived threat from the pandemic before measures were formally implemented. This is not unique to Australian residents; similar patterns have been observed elsewhere as evidenced by Google's mobility

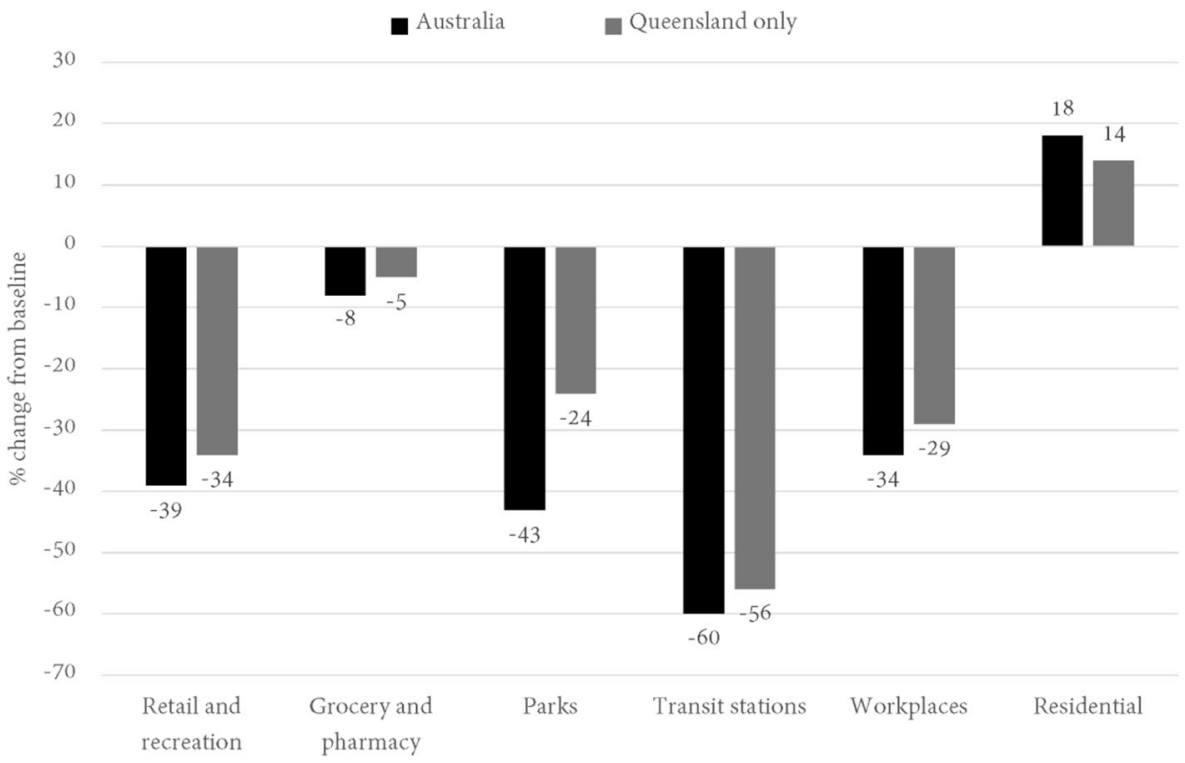

Fig. 3 Changes in mobility (as at 30 April 2020) by location type. Source: Google COVID-19 Community Mobility Report 
data in Europe for example, where residents - informed by the risk of infectionengaged in social distancing before the measures announced by government were implemented (Midoes 2020). In large part, this was also due to many business implementing work-from-home policies and only limiting on-premise work to essential employees.

Limiting the amount of time that people are permitted to spend outside of the home, and the number of people outside the home with whom people may have contact, reduces opportunities for interactions between potential victims and offenders. Spending significantly less time socializing in recreational areas, such as in entertainment precincts, may lead to less public forms of violence. A sizeable proportion of assaultsbetween 37 and $70 \%$, depending on which state or territory-occur in public locations (Australian Bureau of Statistics 2019). We know, for example, that a significant proportion of violent crime in Australia is attributable to the night time economy and peaks on weekends during periods of high alcohol consumption, particularly in major urban centers (Miller et al. 2016). Excessive consumption of alcohol, common in these settings, is directly related to physical aggression and is a contributing factor in physical and sexual violence (Graham et al. 1998). Rates of self-reported involvement in physical aggression in and around licensed premises in the previous 3 months among thousands of patrons surveyed in nine different cities ranged from 7 to $17 \%$ (Miller et al. 2016).

Entertainment precincts are also a known hotspot for sexual violence.

Conversely, the increase in time spent at home increases the risk of violence in residential locations. According to the latest ABS ( 2019) data, between 30 and $63 \%$ of assaults and between 40 and $73 \%$ of sexual assaults normally occur in residential settings (with most jurisdictions closer to the upper end of that range). This might be expected to increase during COVID-19. There is particular concern about the increased risk of family and domestic violence, which is already a significant problem in Australia (Fitz-Gibbon and Meyer 2020; Usher et al. 2020). The most obvious risk is from intimate partner violence, which accounts for more than half of all family violence-related assaults (Australian Bureau of Statistics 2019). Former partners may pose less of a threat (at least in terms of physical violence) in periods of social isolation; however, around four in five assaults by an intimate partner are committed by the victim's current partner (Australian Bureau of Statistics 2019). Adolescent family violence is also an area of concern and, with the closure of schools and many recreational facilities, may increase due to increased contact between young people who use violence and their parents. As well as being at a greater risk of violence in the home due to increased contact with their abuser, victims of family and domestic violence face increasing social isolation, have limited opportunities to seek help from family and friends, may be unable or fearful of seeking help due to surveillance by their partner, or face challenges with seeking assistance from formal support services due to social distancing measures preventing face to face contact (Peterman et al. 2020; van Gelder et al. 2020; Usher et al. 2020). This raises the potential risk of repeat violence.

Of course, not everyone will comply with social distancing measures. Unsurprisingly, there is some overlap between the profile of those people who are less likely to comply and those people who are more likely to be involved in crime. Specifically, Nivette et al. (2020) found that non-compliance was associated with antisocial potential, including delinquent behavior. It is plausible that these non-compliant individuals 
will be more likely to offend, reducing any effect from the changes to routine activities of compliant individuals.

\section{General strain}

The other potential consequence of the Queensland lockdowns is an increase in criminal - especially violent - behavior - that might occur as a result of the emotional and financial pressure of the pandemic. In Australia, there are already signs of the strain on Australian households. One in three Australian households already report being financially worse off (Australian Bureau of Statistics 2020a). Levels of anxiety are also much higher than usually observed (Australian Bureau of Statistics 2020b). The Australian Bureau of Statistics (2020a) reported that $72 \%$ of businesses have experienced a reduced cash flow that is expected to harm business activity and employment over the coming months. In fact, throughout March, these challenging economic circumstances have resulted in a $7.5 \%$ decrease in employee jobs and an $8.2 \%$ reduction in wages paid to employees (Australian Bureau of Statistics 2020c). Unsurprisingly, some employees and sectors have been harder hit than others, with a $33 \%$ reduction in employee jobs for the accommodation and food services sector and a $27 \%$ in the arts and entertainment sectors. The implication of this financial stress is not insubstantial; violence, including domestic violence, is concentrated in areas with higher socio-economic disadvantage (Hulme et al. 2019), while financial stress has been identified as a risk factor for repeat offending (Dowling and Morgan 2016).

The restrictions on movement are likely to be compounded by the negative psychological impacts of quarantine measures. A recent rapid review by Brooks et al. (2020) concluded that there are likely to be wide ranging and long-lasting psychological impacts, including a high prevalence of stress disorders, irritability, emotional disturbance, anger, and depression, among other symptoms. Recent findings from a cohort study showed increased levels of perceived stress and anger among young people during the pandemic (Shanahan et al. 2020). Data from call centers in the USA, for example, reveals substantial increases in calls to mental health and suicide prevention hotlines (Goodman 2020; Jackson 2020). Although this may not, in and of itself, lead to increased violence, people who experience these symptoms may be more likely to engage in substance misuse (Clay and Parker 2020) which, together with poor mental health, is associated with an increased risk of violence (Elbogen and Johnson 2009). Also, there is evidence of increased alcohol consumption in the home due to onpremise restrictions and increased home delivery (Foundation for Alcohol Research \{and Education, 2020). While debate persists regarding the causal role of substance use and domestic violence (Graham et al. 2011), these are situational stressors that can further exacerbate the risk of family and domestic violence.

One criminological theory that is apt to help explain a potential increase in violence, in particular violence in the home, is Agnew's (1992) general strain theory. Recognizing that the early macro-level strain perspectives failed to take into account the social psychological processes involved when perceiving strain, Agnew reframed the theory at the micro-level. Specifically, Agnew posited the existence of three broad categories of strain: (1) failure to achieve positive goals, (2) presentation of noxious stimuli, and (3) removal of positive stimuli. Within the context of COVID-19, it is relatively easy to identify examples of each of these types of strain. For example, being furloughed from 
work is a good example of the first type of strain as people may not be able to pay their rent or mortgage. An example of the second type of strain is the built-up tension that may exist because individuals find themselves in cramped quarters with little room for escape. And finally, with respect to the removal of positive stimuli, lockdowns prevent individuals from visiting restaurants, bars, shopping centers, and gyms — all of which are activities people may enjoy and for which may also offer stress relief.

For Agnew, however, there is more to understanding criminal behavior than just the presence of these types of strain. Most importantly, he contends that these types of strains produce a wide range of negative behaviors within persons including anger, rage, fear, depression, anxiety, and so forth. It is the experience of these negative emotions that, left unchecked by coping mechanisms, are expected to lead to a higher likelihood of criminal behavior-but especially violence.

During the period of enforced social distancing associated with COVID-19, it is easy to envision that Agnew would predict an increase in interpersonal, domestic partneroriented violence because of the anger and rage that may occur because people do not have much physical separation and because the victim may not be able to reach out for help because their aggressor lives with them. With respect to child abuse, there may be reasons to think there would be both an increase and a decrease in real and reported rates of abuse. Child abuse may increase for similar reasons as to partner abuse. A reduction in reported child abuse could be anticipated during school closures given teachers are the ones who are most often able to "see" the after-effects of physical child abuse. At the same time, there is limited evidence of an increase in physical injuries associated with child abuse being reported in some US hospitals due to increased presentations associated with COVID-19(Santhanam 2020). And with respect to property crime, it is expected, within the theory, that many forms of burglaries and thefts would drop because people are home and not out and about, but cybercrime and other fishing-related scams could increase as people use the internet more often.

\section{What trends have been observed around the world?}

Scholars have been quick to examine the impact of COVID-19 on violent crime, particularly in large US cities with open source crime data. Mohler et al. (2020) analyzed daily counts of calls for service and recorded crime in Los Angeles and Indianapolis for several major offense categories. They compared the period after stayat-home orders had been issued (March 20 and March 24, respectively) - regarded as the time period when full social distancing came into effect - to the period prior to school closures. They observed no change in assault/battery calls for service in either city; however, there was a significant increase in domestic violence calls for service of between 13.6 and 15.2 events per day. Domestic violence assaults could not be distinguished from other assaults in recorded crime data. Recorded aggravated assaults (of which domestic violence will account for some) did not change. Mohler et al. (2020) also observed significant declines in burglary and robbery calls for service in Los Angeles and a small increase in vehicle theft, but no change in Indianapolis. In terms of recorded crime, only robbery in Los Angeles was significantly reduced. These findings were reinforced in a second regression that incorporated Google mobility data. Yet, their results are limited because of the short-term analysis and inability to disentangle seasonal trends and more longer-term(yearly) crime patterns. 
Campedelli et al. (2020) analyzed daily recorded crime counts over a 3-year period in Los Angeles using Bayesian structural time-series models, incorporating controls for weather (seasonality) and holiday periods. This approach allowed them to produce a synthetic counterfactual — what would have occurred had there been no containment measures - which they compared with observed crime counts during a period of increasingly stringent social distancing measures in March. They found no impact on homicide, assault with deadly weapons, and intimate partner assault, but observed a decrease in robberies and battery (simple assault) - the latter only during the period with more stringent social distancing measures. Property crimes, including shoplifting and thefts, decreased, as did crime overall.

Most recently, Ashby (2020) analyzed data for 16 large US cities. Similar to Campedelli et al. (2020), Ashby forecasted the expected frequency of crime during the pandemic based on data from 2016 to early 2020, but used seasonal autoregressive integrated moving average models to produce the synthetic counterfactual for the period after January 21 (the first confirmed case of COVID-19 in the USA). There was no change in crime levels between the observed and predicted values before early March, when social distancing measures (like closing schools and then stay-at-home orders) were introduced. In terms of violent crime, there was no impact in any of the cities on serious assaults in public places or in residences. The latter was used as a proxy for domestic violence. There was some evidence of an impact on property crime, including burglary and theft from vehicles; however, Ashby observed significant variation between the cities, with no two cities exhibiting the same trends in crime.

Finally, Piquero et al. (2020) used data from the Dallas, Texas, Police Department in order to examine the extent to which domestic violence incidents increased as a result of the city's stay-at-home orders. Their analysis showed that there was an immediate spike in the first 2 weeks after the stay-at-home order went into effect followed by a decrease in the 2 weeks that followed. At the same time, their analysis also suggested that domestic violence incidents were trending higher just before the stay-at-home orders were implemented, which likely reflects the fact that many people were starting to stay at home before the formal orders were enacted.

In Sweden, where containment measures have been less stringent than elsewhere, Gerell et al. (2020) compared the weekly crime numbers in 2020 with the median from three previous years. There were differences between the observed and expected values for indoor and outdoor assault; however, these differences were relatively small and, in the case of outdoor assault, not consistent for all of the weeks examined. Gerell et al. (2020) also observed declines in residential burglary, commercial burglary, and pickpocketing.

Overall, there is mixed support for the suggestion that COVID-19 and associated containment measures has had an impact violent crime, and in the more robust studies using longer-term time series analysis, there was no evidence of an impact on domestic violence (Ashby 2020; Campedelli et al. 2020; though see Piquero et al. 2020). Importantly, each of these studies has focused on the initial weeks following the introduction of containment measures, meaning that it might still be too early to have detected any meaningful impact on crime. The impact on simple assault in Los Angeles only emerged in the most recent iteration of the analysis (Campedelli et al. 2020), when social distancing measures had become more 
stringent. The limitations of using police recorded crime data to measure certain crime types when reporting rates might also be affected, particularly for domestic violence, were also acknowledged.

\section{How has COVID-19 impacted crime in Australia?}

Most of the evidence around the impact of crime impacts of COVID-19 in Australia is based on media reports, which draw on information supplied by police agencies. Limited detailed analyses have been conducted, although as the pandemic continues, it is likely that more data will become available and studies will be published. Further, it is recognized that many law enforcement agencies and other data custodians will be conducting their own in-house analyses of crime to help inform their respective government's response.

There is emerging evidence of the impact of restrictions on family violence and, to date, that evidence has produced something of a mixed picture. Some police jurisdictions have seen an increase in family violence incidents, others have not. Western Australian Police has reported a 5\% increase (Shepherd 2020), but South Australia recently reported that their numbers have not changed (Australian Broadcasting Corporation 2020b). Victoria Police have reported 14\% of incidents as being related to COVID-19 and the need for victims and perpetrators having to stay at home together (Davey 2020). But there has been no increase in recorded assaults. Most recently, and in the only published analyses that we are aware of, the New South Wales (NSW) Bureau of Crime Statistics and Research concluded there had been no increase in recorded domestic violence (Freeman 2020). Freeman (2020) acknowledges that social isolation may have impacted the willingness or ability of victims to report to police; however, trends in serious forms of violence, less susceptible to changes in reporting rates, were also stable. Still, the study did not involve any time series analysis; rather, the frequency of recorded offenses in March 2020 was compared with March 2019.

Data from other sources has provided a slightly different picture. Fifty percent of domestic violence service providers in NSW reported an increase in demand following the onset of the pandemic in February (Women's Safety NSW 2020). But elsewhere, demand has not increased. In regional NSW, services have reported a decline in calls, raising concerns isolated victims cannot reach out for help (Tate 2020). Similarly, there have been reports of a decrease in calls to domestic violence helplines - by as much as $30 \%$ to 1800 RESPECT have been reported (Talwar 2020)_but these numbers are climbing again (Pearson 2020). Conversely, there has been an increase in calls to men's helplines from perpetrators reaching out for help to stop them from being violent (Tuohy 2020). Finally, trauma surgeons in the Northern Territory have reported a $15 \%$ increase in surgeries related to domestic violence (Davey 2020). However, none of these data sources have been subjected to rigorous analysis.

\section{Current study}

The problem with some of the published studies conducted to date-Australian and overseas - is that they have tended to rely on short time series. The benefit of shorter- 
term studies is that they have used daily offense counts and because of this they are able to detect immediate, short-term changes in crime. However, analyzing short time periods does not account for longer term trends and seasonal variation that might occur, leading to masked or exaggerated effects. The same is true of studies that compare data for March 2020 with the same month in the previous year (or years). Our study overcomes these limitations by using officially recorded violent crime rates to model the series trend over 6 years between February 2014 and 2020. We then compute 6-month ahead forecasts for the various crime types and compare these with the observed rates for March and April 2020, when COVID-19 social distancing regulations were in place.

\section{Methodology}

\section{Data}

These data are drawn from the Queensland Government's Open Data Portal (Queensland Government 2020). The ODP reports state-wide monthly offense rates per 100,000 of the Queensland population. The most recent addition to these data were for the month of April 2020 - 1 month after the state of Queensland introduced significant social distancing regulations. For this study, we use the offense rates for four types of violent crime - common assault, serious assault, sexual offenses, and breaches of domestic violence orders.

\section{Analytical approach}

For each of the four violent offense categories, we operationalize an Auto Regressive Integrated Moving Average (ARIMA) model on the monthly offense rate between February 2014 and February 2020.1 ARIMA models are a specific type of time series forecasting technique which capitalize on several key time-seriesparameters - the series trend and seasonality, its lagged auto-correlations and its lagged partial autocorrelations (correlations between residual errors). Put simply, past values of each time series are used to identify predictable patterns. These patterns are then used to specify a statistical model from which forecasts can be computed. Like all models, the relative accuracy of any forecast depends on the strength of the relationship between past and future values.

In each series, we exclude from the analysis the observed value for March 2020 onwards since this is the month when social distancing restrictions were first introduced in Queensland. ${ }^{1}$ Each series also requires a unique ARIMA specification, depending on the presence (or absence) of seasonality and the unique nature of the series trend, autocorrelation and partial auto-correlation.

Procedurally, we begin each model with a statistical assessment of the presence of a unit-root (non-stationarity). A unit-root is a stochastic trend which represents a

\footnotetext{
${ }^{1}$ We note that in Queensland, violent crime rates began increasing in late 2013 following a long and protracted decline. There are not yet any documented explanations for that change and so we have elected to model the series for the full 6-year period following the structural break.
} 
systematic pattern that is unpredictable. Any time-series which evidence a unit-root must be first de-seasonalized or first-differenced before ARIMA modeling can be performed. To explore stationarity, the augmented Dickey-Fuller(ADF) test is used. The null hypothesis of the ADF test is that raw series is non-stationary (i.e., includes a unit-root). Failure to reject the null-hypothesis at $p<0.05$ indicates the presence of a unit-root and necessitates its removal.

Where there is some evidence of non-stationarity, the unit root is removed by seasonal and trend differencing. The raw series is used for subsequent ARIMA modeling if the ADF test indicates stationarity. If not, the seasonality-differenced and first-differenced series is used, either separately or combined, depending on which produces the superior fit to the data. The base seasonality adjustment is $\operatorname{SARIMA}(0,1,0,12)$, where the purpose of seasonality differencing is to parameterize the additive seasonal patterns in the raw data. Second, and where needed, nonstationarity in the trend is removed using first-differencing. The base adjustment for non-stationarity in the trend is $\operatorname{ARIMA}(0,1,0)$. Therefore, a series that requires both trend and seasonality differencing is known as $\operatorname{ARIMA}(0,1,0) \operatorname{SARIMA}(0,1,0,12)$.

Subsequent to any adjustments, each offense series is then explored using autocorrelation(AC) and partial auto-correlation(PAC) plots. These plots help to determine the most likely specification of the seasonal and trend-level moving average (MA) and auto-regressive(AR) parameters. From here, the modeling is iterative and each specification seeks to identify the unique $\mathrm{AR}$ and MA specifications which best fit the observed data. As with all modeling, there is a trade-off between parsimony and best fit, so we use the Akaike information criteria (AIC) and the Bayesian information criteria (BIC) to guide final model selection.

At the conclusion of the modeling procedure for each violent offense, we use the final ARIMA specification to forecast both point estimates and their mean square errors (MSE). The MSE is used to calculate $95 \%$ confidence intervals up to and including September 2020. We then compare the observed offense rate for March and April 2020 to the forecasted point estimate for the same month. We also consider its position within the confidence interval of the forecast and we only conclude that the offense rate has changed under COVID-19 conditions if the observed value (for March and April 2020) falls outside the upper or lower bounds of the $95 \%$ confidence interval. ${ }^{2}$

\section{Results}

\section{Common assault}

Between February 2014 and February 2020, the rate of common assault in Queensland has fluctuated between 9.0 and 15.5 recorded offenses per 100,000 of the population.

\footnotetext{
${ }^{2}$ A $95 \%$ confidence interval in this case suggests the range in which $95 \%$ of plausible values will fall given the statistical relationships in the historical data. Conversely, it is possible that $5 \%$ of values could fall outside that range and still be "plausible" outcomes. Ideally, to be most confident of a COVID-19 effect, we would wait to see if two or more successive months were observed beyond the forecasted confidence interval. However, since Queensland relaxed social distancing regulations in May 2020, and since these data are only produced by Queensland police as monthly crime rates, we have only the month of April to explore the $100 \%$ dosage effect of social distancing across Queensland.
} 
Table 1 ARIMA model selection for common assault (Feb 2014-Feb 2020)

\begin{tabular}{|c|c|c|c|c|c|c|c|}
\hline Model & Description & Specification & Obs & 11(model) & df & AIC & $\mathrm{BIC}$ \\
\hline 1 & Constant only & $\operatorname{ARIMA}(0,0,0) \operatorname{SARIMA}(0,0,0,12)$ & 73 & -137.31 & 2 & 278.62 & 283.20 \\
\hline 2 & Seasonal differencing & $\operatorname{ARIMA}(0,0,0) \operatorname{SARIMA}(0,1,0,12)$ & 73 & -125.93 & 1 & 253.87 & 256.16 \\
\hline 3 & Trend differencing & $\operatorname{ARIMA}(0,1,0) \operatorname{SARIMA}(0,0,0,12)$ & 73 & -120.77 & 1 & 243.54 & 245.83 \\
\hline 4 & $\begin{array}{l}\text { Seasonal and trend } \\
\text { differencing }\end{array}$ & $\operatorname{ARIMA}(0,1,0) \operatorname{SARIMA}(0,1,0,12)$ & 73 & -116.29 & 1 & 234.58 & 236.87 \\
\hline 5 & $\begin{array}{l}\text { Model } 4 \text { with seasonal } \\
\text { MA1 }\end{array}$ & $\operatorname{ARIMA}(0,1,0) \operatorname{SARIMA}(0,1,1,12)$ & 73 & -105.11 & 1 & 212.21 & 214.50 \\
\hline 6 & $\begin{array}{l}\text { Model } 4 \text { with seasonal } \\
\text { AR1 }\end{array}$ & $\operatorname{ARIMA}(0,1,0) \operatorname{SARIMA}(1,1,0,12)$ & 73 & -113.39 & 2 & 230.78 & 235.36 \\
\hline 7 & $\begin{array}{l}\text { Model } 4 \text { with seasonal } \\
\text { AR1 and MA1 }\end{array}$ & $\operatorname{ARIMA}(0,1,0) \operatorname{SARIMA}(1,1,1,12)$ & 73 & -104.49 & 2 & 212.97 & 217.55 \\
\hline 8 & Model 5 with trend MA1 & ARIMA $(0,1,1) \operatorname{SARIMA}(0,1,1,12)$ & 73 & -105.10 & 3 & 216.20 & 223.07 \\
\hline 9 & Model 5 with trend AR1 & $\operatorname{ARIMA}(1,1,0) \operatorname{SARIMA}(0,1,1,12)$ & 73 & -107.99 & 3 & 221.98 & 228.85 \\
\hline 10 & $\begin{array}{l}\text { Model } 5 \text { with trend AR1 } \\
\text { and MA1 }\end{array}$ & $\operatorname{ARIMA}(1,1,1) \operatorname{SARIMA}(0,1,1,12)$ & 73 & -104.60 & 4 & 217.21 & 226.37 \\
\hline 11 & $\begin{array}{l}\text { Model } 4 \text { with trend } \\
\text { MA1 and MA12 }\end{array}$ & $\operatorname{ARIMA}(0,1,1$ 12)SARIMA $(0,1,0,12)$ & 73 & -101.99 & 3 & 209.97 & 216.84 \\
\hline
\end{tabular}

The final model indicated in italic. Source: Queensland Offence rates, Open Data Portal

The observed rate in March 2020 was 14.6 per 100,000, up from the previous month $(13.5$ per 100,000$)$ and slightly lower than the same time in the previous year $(15.1$ per 100,000). Comparative tests (Table 1) confirm the need for both seasonality adjustment and trend-level first-differencing and inspection of the $\mathrm{AC}$ and $\mathrm{PAC}$ plots indicate significant auto-correlations at lags 1 and 12 .

The specification that best fit these data was $\operatorname{ARIMA}(0,1,1 \quad 12)$ SARIMA $(0,1,0,12)(\mathrm{AIC}=209.97)$. The modelled parameters are provided in Table 2 and the dynamic forecasts for March and April 2020 are provided in Fig. 4. We note that the observed rate $(14.6$ per 100,000) of common assault for Marchthe month when social distancing regulations first came into effect-was almost equal to the forecasted rate $(14.7$ per 100,000$)$ for that month. In April, the common assault rate fell further to 10.9 offenses per 100,000, which was below the forecast $(12.1$ per 100,000$)$ but still within the $95 \%$ confidence interval of the prediction for that month. We conclude, therefore, that there is insufficient evidence to suggest

Table 2 ARIMA model parameters for Common Assault (Feb 2014-Feb 2020)

\begin{tabular}{lccr}
\hline & Coeff & Std. err. & $p$ \\
\hline Trend & & & 0.00 \\
MA1 & -0.45 & 0.13 & 0.00 \\
MA12 & -0.55 & 0.18 & 0.00 \\
/sigma & 0.93 & 0.09 & \\
\hline
\end{tabular}

Model: ARIMA(0,1,1 12) SARIMA(0,1,0,12). Source: Queensland Offence rates, Open Data Portal 


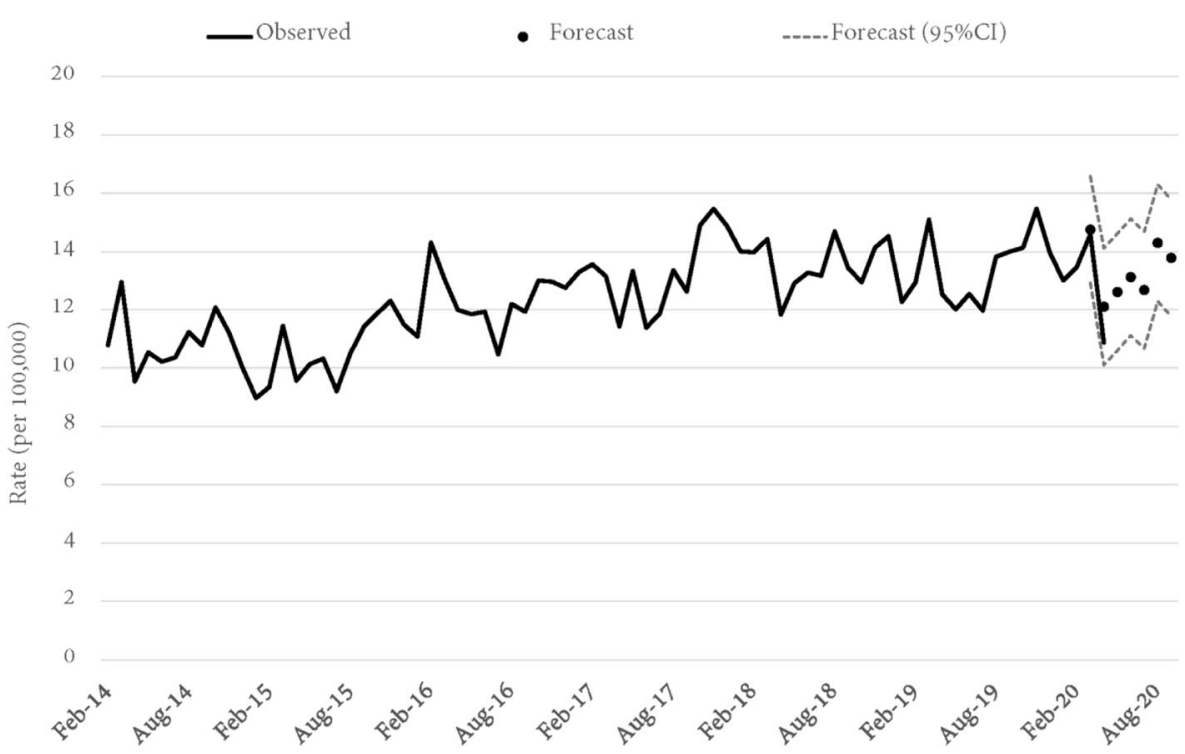

Fig. 4 Long-term common assault rates (observed rates and ARIMA forecasts). Source: Queensland Offence rates, Open Data Portal

that common assault rates have been negatively impacted during the first 2 months of COVID-19.

As a post-script, we think it is important here to acknowledge that the rate of common assault in Queensland in April 2020 was the lowest it has been in more than 3 years. Not since July 2016 has the recorded rate of common assault fallen below 11 offenses per 100,000 . This is a striking and notable result, even though the statistical

Table 3 ARIMA model selection for serious assault (Feb 2014-Feb 2020)

\begin{tabular}{|c|c|c|c|c|c|c|c|}
\hline Model & Description & Specification & Obs & 11(model) & $\mathrm{df}$ & AIC & BIC \\
\hline 1 & Constant only & $\operatorname{ARIMA}(0,0,0) \operatorname{SARIMA}(0,1,0,12)$ & 73 & -162.89 & 2 & 329.77 & 334.35 \\
\hline 2 & Seasonal differencing & $\operatorname{ARIMA}(0,0,0) \operatorname{SARIMA}(0,1,0,12)$ & 73 & -133.92 & 1 & 269.83 & 272.12 \\
\hline 3 & Trend differencing & $\operatorname{ARIMA}(0,1,0) \operatorname{SARIMA}(0,0,0,12)$ & 73 & -123.21 & 1 & 248.43 & 250.72 \\
\hline 4 & $\begin{array}{l}\text { Seasonal and trend } \\
\text { differencing }\end{array}$ & $\operatorname{ARIMA}(0,1,0) \operatorname{SARIMA}(0,1,0,12)$ & 73 & -118.66 & 1 & 239.33 & 241.62 \\
\hline 5 & $\begin{array}{l}\text { Model } 4 \text { with seasonal } \\
\text { MA1 }\end{array}$ & $\operatorname{ARIMA}(0,1,0) \operatorname{SARIMA}(0,1,1,12)$ & 73 & -106.03 & 1 & 214.07 & 216.36 \\
\hline 6 & $\begin{array}{l}\text { Model } 4 \text { with seasonal } \\
\text { AR1 }\end{array}$ & $\operatorname{ARIMA}(0,1,0) \operatorname{SARIMA}(1,1,0,12)$ & 73 & -113.10 & 2 & 230.19 & 234.78 \\
\hline 7 & $\begin{array}{l}\text { Model } 4 \text { with seasonal } \\
\text { AR1 and MA1 }\end{array}$ & $\operatorname{ARIMA}(0,1,0) \operatorname{SARIMA}(1,1,1,12)$ & 73 & -105.90 & 3 & 217.80 & 224.67 \\
\hline 8 & Model 5 with trend MAI & $\operatorname{ARIMA}(0,1,1) \operatorname{SARIMA}(0,1,1,12)$ & 73 & -101.75 & 3 & 209.51 & 216.38 \\
\hline 9 & Model 5 with trend AR1 & $\operatorname{ARIMA}(1,1,0) \operatorname{SARIMA}(0,1,1,12)$ & 73 & -105.08 & 3 & 216.16 & 223.03 \\
\hline 10 & $\begin{array}{l}\text { Model } 5 \text { with trend AR1 } \\
\text { and MA1 }\end{array}$ & $\operatorname{ARIMA}(1,1,1) \operatorname{SARIMA}(0,1,1,12)$ & 73 & -101.65 & 4 & 211.30 & 220.47 \\
\hline
\end{tabular}

The final model indicated in italic. Source: Queensland Offence rates, Open Data Portal 
evidence suggests that this could have occurred irrespective of COVID-19. Importantly, this result exemplifies the challenge and uniqueness of conducting this analysis in the southern hemisphere where the crimes rates are expected to fall naturally during the colder months.

\section{Serious assault}

Since February 2014, the rate of serious assault in Queensland has fluctuated between 12.2 and 21.3 offenses per 100,000 of the population. In March 2020, the observed rate was 18.9 per 100,000 . This was lower than the previous month $(19.5$ per 100,000) and lower than at the same time in the previous year (19.4 per 100,000). Comparative model tests (Table 3) indicate the need for both trend and seasonality differencing, which $\mathrm{AC}$ and PAC plots indicate the need for seasonal AR and trend-level MA parameters.

The best fitting model was specified as $\operatorname{ARIMA}(1,1,0) \operatorname{SARIMA}(0,1,1,12)$ $(\mathrm{AIC}=209.51)$ and the final modelled parameters are provided in Table 4. Overall, the model captures both the series trend and its seasonal peaks and troughs; however, there is still some period-specific variability that was not easily predicted. Overall, the observed rate of serious assault in March 2020 (18.9 per 100,000) was lower than forecast from the historical series (20.2 per 100,000), but not beyond the range of statistically plausible values for that month (18.3-22.1 per 100,000) (Fig. 5). In April, the serious assault rate plummets (to 12.7 per $100,000)$, well below the series forecast and well outside the confidence interval (15.4 to 19.7 per 100,000 ). In fact, not since July 2015 has the serious assault rate been as low as it was in April 2020 and the statistical evidence suggests that this decline would not have occurred in the absence of some significant exogenous changes.

\section{Sexual offending}

Since February 2014, sexual offense rates in Queensland have ranged between 8.3 and 15.4 per 100,000 of the population. The observed result for March 2020 was 9.2 per 100,000 . This was lower than in the previous month $(11.3$ per $100,000)$ and lower than the same time in the previous year $(14.5$ per 100,000$)$. The ADF test confirmed that the series is stationary and comparative model tests

Table 4 ARIMA model parameters for serious assault (Feb 2014-Feb 2020)

\begin{tabular}{lccc}
\hline & Coeff & Std. err. & $p$ \\
\hline Trend & & & \\
MA1 & -0.58 & 0.12 & 0.00 \\
Seasonal & & & 0.01 \\
AR1 & -0.33 & 0.12 & 0.00 \\
/sigma & 0.96 & 0.08 & \\
\hline
\end{tabular}

Model: ARIMA(0,1,1) SARIMA(1,1,0,12). Source: Queensland Offence rates, Open Data Portal 

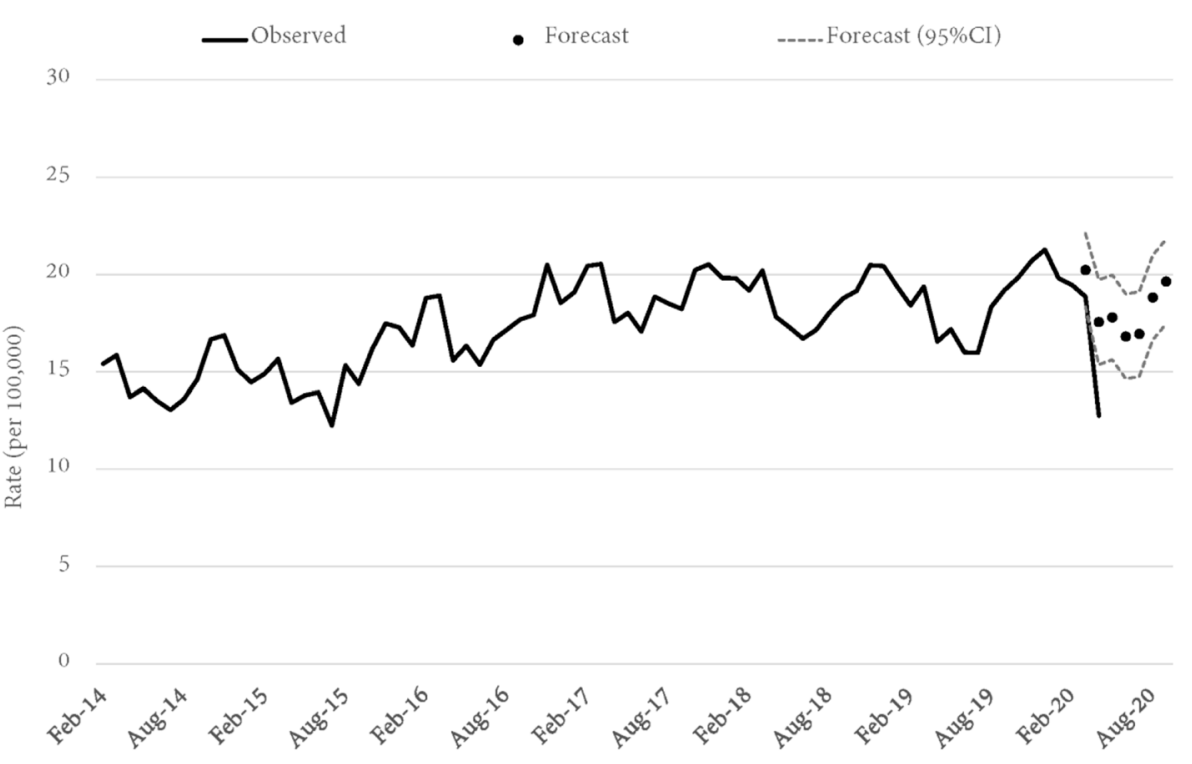

Fig. 5 Long-term serious assault rates (observed rates and ARIMA forecasts). Source: Queensland Offence rates, Open Data Portal

(Table 5) confirm that neither trend nor seasonality differencing was required. Inspection of the $\mathrm{AC}$ and $\mathrm{PAC}$ plots indicate significant auto-correlation at lags 1 and 2 and so several specifications of the AR and MA parameters were compared.

The final and best fitting model-ARIMA $(0,0,2)$ - required two MA parameters at lags 1 and 2. The model parameters are presented in Table 6. It was apparent from the fitted data that the model performs relatively poorly and does

Table 5 ARIMA model selection for sexual offenses (Feb 2014-Feb 2020)

\begin{tabular}{|c|c|c|c|c|c|c|c|}
\hline Model & Description & Specification & Obs & $11($ model $)$ & df & AIC & BIC \\
\hline 1 & Constant only & $\operatorname{ARIMA}(0,0,0) \operatorname{SARIMA}(0,1,0,12)$ & 73 & -133.77 & 2 & 271.54 & 276.12 \\
\hline 2 & Seasonal differencing & $\operatorname{ARIMA}(0,0,0) \operatorname{SARIMA}(0,1,0,12)$ & 73 & -153.33 & 1 & 308.66 & 310.95 \\
\hline 3 & Trend differencing & $\operatorname{ARIMA}(0,1,0) \operatorname{SARIMA}(0,0,0,12)$ & 73 & -154.86 & 1 & 311.72 & 314.01 \\
\hline 4 & $\begin{array}{l}\text { Seasonal and trend } \\
\text { differencing }\end{array}$ & $\operatorname{ARIMA}(0,1,0) \operatorname{SARIMA}(0,1,0,12)$ & 73 & -173.67 & 1 & 349.35 & 351.64 \\
\hline 5 & Model 1 with trend AR1 & $\operatorname{ARIMA}(1,0,0)$ & 73 & -133.24 & 3 & 272.49 & 279.36 \\
\hline 6 & Model 1 with trend MA1 & $\operatorname{ARIMA}(0,0,1)$ & 73 & -133.37 & 3 & 272.75 & 279.62 \\
\hline 7 & $\begin{array}{l}\text { Model } 1 \text { with trend AR1 } \\
\text { and MA1 }\end{array}$ & $\operatorname{ARIMA}(1,0,1)$ & 73 & -133.14 & 4 & 274.28 & 283.44 \\
\hline 8 & Model 1 with trend AR2 & $\operatorname{ARIMA}(2,0,0)$ & 73 & -132.60 & 4 & 273.20 & 282.36 \\
\hline 9 & Model 1 with trend MA2 & $\operatorname{ARIMA}(0,0,2)$ & 73 & -130.64 & 4 & 269.29 & 278.45 \\
\hline 10 & $\begin{array}{l}\text { Model } 1 \text { with trend AR2 } \\
\text { and MA2 }\end{array}$ & $\operatorname{ARIMA}(2,0,2)$ & 73 & -129.26 & 6 & 270.52 & 284.26 \\
\hline
\end{tabular}

The final model is indicated in italic. Source: Queensland Offence rates, Open Data Portal 
Table 6 ARIMA model parameters for sexual offenses (Feb 2014-Feb 2020)

\begin{tabular}{lrll}
\hline & Coeff & Std. err. & $p$ \\
\hline Trend & & & \\
MA1 & 0.24 & 0.12 & 0.04 \\
MA2 & 0.36 & 0.11 & 0.00 \\
Constant & 10.96 & 0.16 & 0.00 \\
/sigma & 1.45 & 0.31 & 0.00 \\
\hline
\end{tabular}

Model: ARIMA $(0,0,2)$. Source: Queensland Offence rates, Open Data Portal

not adequately capture the high degree of volatility evidenced across the time series. In other words, there is significant fluctuation in the series which has no discernible or reliably predictable pattern. As for the observed rate of sexual offending in March 2020, the rate $(9.2$ per 100,000) was considerably lower than forecast by the model (11.1 per 100,000) (Fig. 6) but within the boundary of plausible outcomes (8.3 to 13.9 per 100,000$)$ given the history of the series. In April, the sexual assault rate fell again to 8.3 per 100,000 and this observed rate fell beyond the lower limit of the confidence interval for that month. It is notable that the rate of sexual offending in April 2020 was the lowest recorded in the 6year series.

\section{Breaches of domestic violence orders}

The rate at which domestic violence orders are breached in Queensland has increased steadily between 2014 and 2020. In early 2014, the breach rate averaged at 26 per

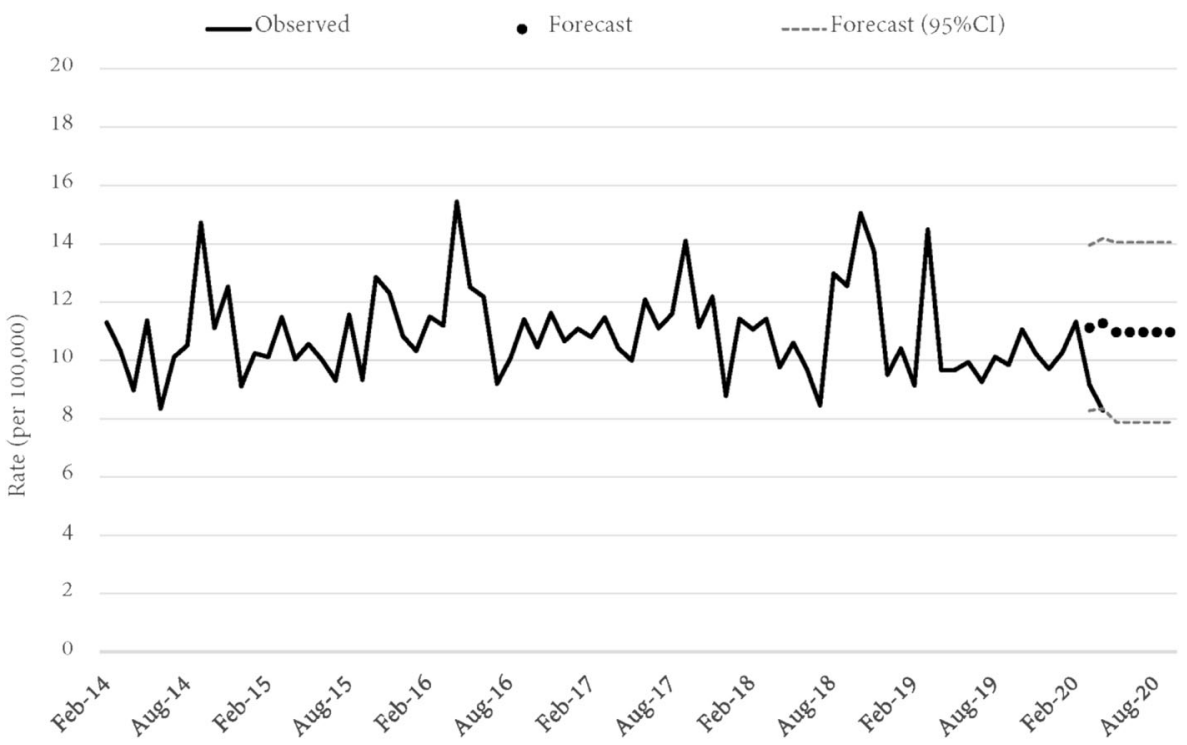

Fig. 6 Long-term sexual offense rates (observed rates and ARIMA forecasts). Source: Queensland Offence rates, Open Data Portal 
Table 7 ARIMA model selection for domestic violence breach offenses (Feb 2014-Feb 2020)

\begin{tabular}{|c|c|c|c|c|c|c|c|}
\hline Model & Description & Specification & Obs & $11($ model $)$ & df & AIC & $\mathrm{BIC}$ \\
\hline 1 & Constant only & $\operatorname{ARIMA}(0,0,0) \operatorname{SARIMA}(0,1,0,12)$ & 73 & -263.96 & 2 & 531.92 & 536.50 \\
\hline 2 & Seasonal differencing & $\operatorname{ARIMA}(0,0,0) \operatorname{SARIMA}(0,1,0,12)$ & 73 & -238.26 & 1 & 478.52 & 480.81 \\
\hline 3 & Trend differencing & $\operatorname{ARIMA}(0,1,0) \operatorname{SARIMA}(0,0,0,12)$ & 73 & -197.05 & 1 & 396.09 & 398.38 \\
\hline 4 & $\begin{array}{l}\text { Seasonal and trend } \\
\text { differencing }\end{array}$ & $\operatorname{ARIMA}(0,1,0) \operatorname{SARIMA}(0,1,0,12)$ & 73 & -182.59 & 1 & 367.18 & 369.47 \\
\hline 5 & $\begin{array}{l}\text { Model } 4 \text { with seasonal } \\
\text { MA1 }\end{array}$ & $\operatorname{ARIMA}(0,1,0) \operatorname{SARIMA}(0,1,1,12)$ & 73 & -172.76 & 2 & 349.53 & 354.11 \\
\hline 6 & $\begin{array}{l}\text { Model } 4 \text { with seasonal } \\
\text { AR1 }\end{array}$ & $\operatorname{ARIMA}(0,1,0) \operatorname{SARIMA}(1,1,0,12)$ & 73 & -176.44 & 2 & 356.88 & 361.46 \\
\hline 7 & $\begin{array}{l}\text { Model } 4 \text { with seasonal } \\
\text { AR1 and MA1 }\end{array}$ & $\operatorname{ARIMA}(0,1,0) \operatorname{SARIMA}(1,1,1,12)$ & 73 & -172.10 & 2 & 348.19 & 352.77 \\
\hline 8 & Model 7 with trend MA1 & $\operatorname{ARIMA}(0,1,1) \operatorname{SARIMA}(1,1,1,12)$ & 73 & -166.02 & 4 & 340.03 & 349.19 \\
\hline 9 & Model 7 with trend AR1 & $\operatorname{ARIMA}(1,1,0) \operatorname{SARIMA}(1,1,1,12)$ & 73 & -165.11 & 3 & 336.23 & 343.10 \\
\hline 10 & $\begin{array}{l}\text { Model } 7 \text { with trend AR2 } \\
\text { and MA2 }\end{array}$ & $\operatorname{ARIMA}(1,1,1) \operatorname{SARIMA}(1,1,1,12)$ & 73 & -165.11 & 4 & 338.23 & 347.39 \\
\hline 11 & Model 5 with trend AR2 & $\operatorname{ARIMA}(1,1,0) \operatorname{SARIMA}(0,1,1,12)$ & 73 & -165.87 & 3 & 337.75 & 344.62 \\
\hline
\end{tabular}

The final model is indicated in italic. Model 9 could not estimate a parameter for the seasonal AR1 term and the term was omitted from the model. Model 11 removes the SAR1 term and provides a superior fit to the data. Source: Queensland Offence rates, Open Data Portal

100,000 of the population. By 2020, that had increased to a high of 62 per 100,000. The observed DVO breach rate in March 2020 was 57.5 per 100,000 which was higher than in the previous month $(55.2$ per 100,000) and higher than it was in March of the previous year $(52.0$ per 100,000). However, we caution here on the interpretation of these rates since they are not adjusted for the number of actual domestic violence orders which are active nor the rate at which they are issued by the courts. In the present data, the longer-term upward trend, including in the past 12 months, is likely a strong reflection of the increased number of orders being made by the courts and not necessarily any trend in the relative rate of breach events when calculated as function of the number of active orders.

Nevertheless, the ADF statistic confirmed that without adjustment the DVO breach series is non-stationary $(\mathrm{ADF}=-1.628, p=0.47)$. Comparative model analysis

Table 8 ARIMA model parameters for domestic violence order breach offenses (Feb 2014-Feb 2020)

\begin{tabular}{lclc}
\hline & Coeff & Std. err. & $p$ \\
\hline Trend & & & \\
AR1 & -0.42 & 0.09 & 0.00 \\
Seasonal & & & \\
MA1 & -0.80 & 0.24 & 0.00 \\
/sigma & 2.17 & 0.26 & 0.00 \\
\hline
\end{tabular}

Model: ARIMA(1,1,0) SARIMA(0,1,1,12). Source: Queensland Offence rates, Open Data Portal 


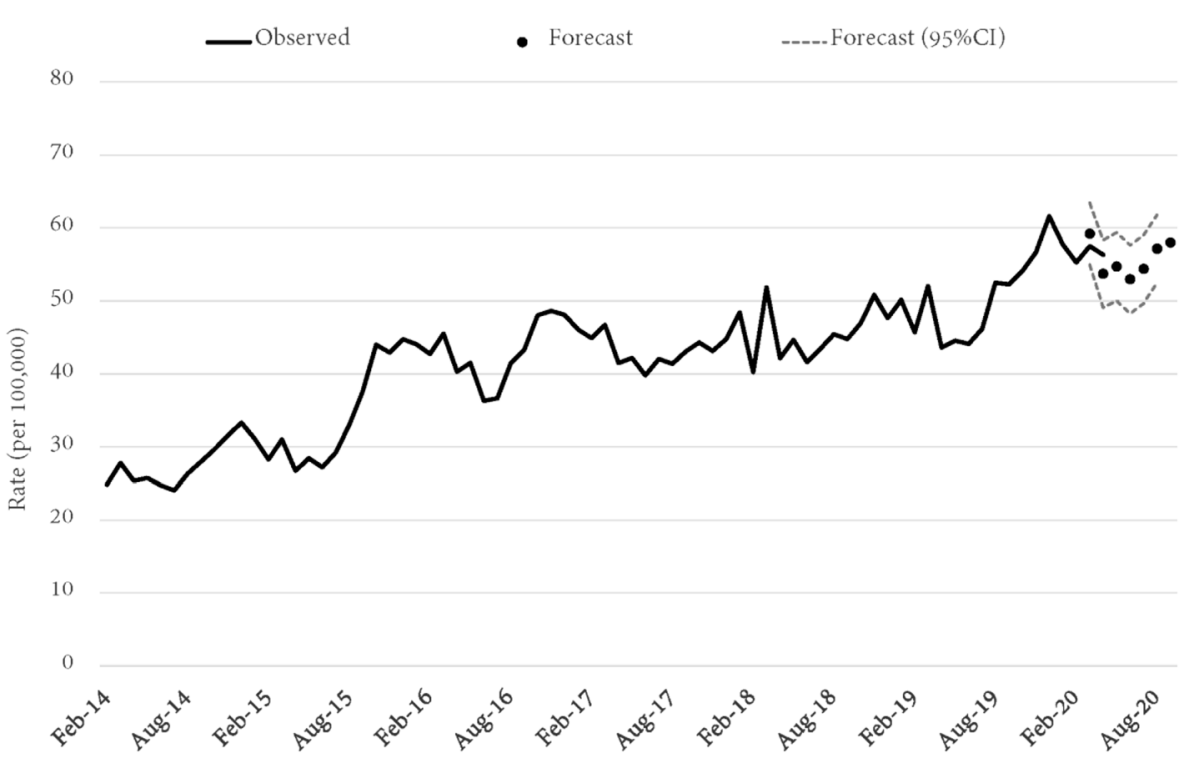

Fig. 7 Short-term domestic violence order breach rates (observed rates and ARIMA forecasts). Source: Queensland Offence rates, Open Data Portal

(Table 7) indicated the need for both seasonal and trend differencing. AC and PAC plots suggested significant auto-correlations and partial auto-correlations at lag 1 .

The best fitting model-ARIMA(1,1,0) SARIMA(0,1,1,12) - required an AR parameter at lag 1 for the trend and an MA parameter at lag 1 in the seasonal pattern $(\mathrm{AIC}=337.75)$. The final model specifications can be found in Table 8; the modelled results are graphically presented in Fig. 7. Overall, the model fit the data with surprising precision. As for the observed breach rate of domestic violence orders in March 2020, the rate $(57.5$ per 100,000$)$ was lower than forecast by the model $(59.2$ per 100,000$)$ (Fig. 7) but well within the range (54.9 to 63.4 per 100,000$)$ of plausible values given the history of the series. In April, the DVO breach rate declined slightly, although not as much as was forecast and remained within the confidence interval. We conclude that there is insufficient evidence to suggest that breaches of domestic violence orders increased or decreased in the context of COVID-19.

\section{Discussion}

The COVID-19 pandemic has had deleterious consequences on the health and wellbeing of individuals worldwide. One outcome of this easily contagious and deadly disease was the response that governments had with respect to travel restrictions, social distancing recommendations, and lockdown orders. And one potential outcome associated with these policies - especially social distancing and stay-at-homeedicts - is the potential for increases in crime, especially interpersonal violent offenses. Accordingly, this study offers one of the first Australian-based analyses of the extent to which crime has changed during the COVID-19 pandemic. 
Specifically, we used an iterative univariate ARIMA framework to model the 6-year trend in the state-wide rates of four violent crime types (common assault, serious assault, sexual offenses, and breaches of domestic violence orders) in Queensland, Australia. We capitalize on the period-by-period and seasonal patterns to generate dynamic forecasts (and their 95\% confidence intervals) for comparison with the observed rates for March 2020. We conclude that, while in none of the four violent crime categories was the rate of recorded crime for March significantly different from the forecast, the rate of recorded serious assault and sexual offending was significantly lower in April. This delayed effect is likely a consequence of the incremental measures that were introduced and the timing of these measures. March 2020 was the month in which the most significant social distancing rules were first introduced in Queensland. However, their introduction occurred in the second half of the month and Google's mobility trend data showed there was a large but gradual decrease in the use of public spaces and an increase in time spent at home, towards the end of March. The impact of these containment measures, particularly in terms of influencing routine activities, was therefore not observed until April. This was consistent with the findings of Campedelli et al.'s (2020) study of assaults in Los Angeles, where a reduction was not observed until the more stringent stay-at-home measures were introduced. Importantly, the effect of major job losses and associated financial stress may not become evident until future months. The dynamic forecasts presented in this study, and their confidence intervals, will be a useful tool in making an assessment as to whether the strain caused by COVID-19 impacts violent crime in the longer term.

In the absence of more detailed data, it is difficult to offer definitive explanations for the different trends observed for the four crime categories reported here. It is possible that the decline in serious assault and sexual offenses is largely a function of the impact of containment measures on the night time economy, which have seen these major weekend attractions all but shutdown. It is well-known that alcohol intoxication is associated with more serious forms of violence and is a contributing factor in a large number of sexual assaults. It seems unlikely that crimes associated with the night time economy-particularly less serious common assaults - have not been affected to a larger degree by the closures. Violence in the night time economy accounts for a significant proportion of violence overall (Miller et al. 2016). It is plausible that the lack of an observable effect in common assault is a function of competing trends between violence occurring in different contexts. The decrease in violence associated with the night time economy may be offset by increases in assaults in residential settings, especially domestic violence. This can only be determined through a more detailed analysis of data on offense location, relationship between offender and victim, alcohol and drug involvement, and so on.

Yet, there are also limitations associated with relying on recorded crime data to measure changes in violence, particularly violence in the home. While there is widespread concern about the impact of containment measures on domestic violence, this does not necessarily mean this would translate to an increase in recorded assault. We know that a significant proportion of violent crime goes unreported to police. Although the analysis of serious violence addresses this to some extent (serious violence is more likely to come to the attention of police), we cannot assume that the rate of reporting has remained stable for common assault or sexual offenses. This is particularly important in the context of domestic violence, which often goes unreported to police 
(Voce and Boxall 2018) and for sexual assault that is perpetrated by family members. Advocates and academics have voiced concerns regarding the inability of victims to reach out for help because of isolation from family, friends and support services, fear of the abuser with whom they reside, and the challenges with seeking assistance due to social distancing measures (Fitz-Gibbon and Meyer 2020; Peterman et al. 2020; van Gelder et al. 2020). We have attempted to provide some insight into this by examining the domestic violence order breach rates, but again, we are hesitant about interpreting these data as a true measure of the extent of domestic violence. As with any procedural offense, the breach rate may be influenced by the enforcement practices of police and/ or the willingness of victims to report in these unprecedented circumstances. The fact that domestic violence breach offenses have not declined may reflect a sustained level of reporting of breaches by those victims who have already been in contact with police and the criminal justice system. One option worthy of further consideration in the absence of open access to data on domestic violence-related offenses would be a more detailed analysis of violent offense victimization rates by victim sex and, specifically, the long-term trend in the proportion of adult assault victims who were female. Although these data themselves suffer a number of limitations, they would provide some signal of a shift from community to home-based violence.

We believe that our effort offers an important first step in trying to understand the crime implications of the COVID-19 pandemic and associated containment measures in the Australian context. Our univariate ARIMA models provide an important opportunity for a rapid and robust assessment. Ideally, these Queensland data will soon be complemented by equivalent analyses conducted with data from other Australian jurisdictions, once they are publicly available and offer a nice counterpoint to the research in the USA and elsewhere in order to provide a more complete picture of the government's policy responses to COVID-19. At present, there does not seem to be a crime-exacerbating effect of some of these policies, at least with respect to officially recorded crime. Only through continued data collection and analyses will this portrait begin to be filled out. And in this regard, it will be just as important to track any changes in crime rates when these restrictions are loosened and potentially eliminated. We also hope that researchers will engage in a qualitative data collection to ask respondents about how they dealt with the various policy proscriptions and how they adapted to them vis-à-vis the strainful experiences that may have ensued. Only through the combination of quantitative and qualitative data will social scientists have a complete understanding of COVID-19.

\section{References}

Agnew, R. (1992). Foundation for a general strain theory of crime and delinquency. Criminology, 30(1), 4788. https://doi.org/10.1111/j.1745-9125.1992.tb01093.x.

Ashby, M. P. J. (2020). Initial evidence on the relationship between the coronavirus pandemic and crime in the United States. Crime Science, 9(1), 6. https://doi.org/10.1186/s40163-020-00117-6.

Australian Broadcasting Corporation. (2020a). Coronavirus restrictions will soon be eased in Queensland and WA. What about other states? [ABC News]. Retrieved May 8, 2020, from https://www.abc.net. au/news/2020-04-26/state-by-state-breakdown-of-coronavirus-restrictions/12186302.

Australian Broadcasting Corporation. (2020b). SA police says no spike in domestic violence amid coronavirus restrictions, despite alleged murder [ABC news]. Retrieved April 27, 2020, from https://www.abc.net. au/news/2020-04-20/police-say-no-domestic-violence-spike-in-sa-during-coronavirus/12165598. 
Australian Bureau of Statistics. (2019). Recorded crime-victims, Australia, 2018 (Cat no. 4510.0). Australian Bureau of Statistics. Retrieved April 28, 2020, from https:/www.abs.gov.au/AUSSTATS/abs@. nsf/DetailsPage/4510.02018?OpenDocument.

Australian Bureau of Statistics. (2020a). Business indicators, business impacts of COVID-19, April 2020 (Cat. No. 5676.0.55.003). Australian Bureau of Statistics. Retrieved May 7, 2020, from https://www.abs.gov. au/ausstats/abs\%5C\%40.nsf/mediareleasesbyCatalogue/49F8475B31112582CA25853600764041.

Australian Bureau of Statistics. (2020b). Household impacts of COVID-19 survey, 14-17 Apr 2020 (Cat. No. 4940.0). Australian Bureau of Statistics. Retrieved May 7, 2020, from https://www.abs.gov. au/ausstats/abs\%40.nsf/mediareleasesbyCatalogue/DB259787916733E4CA25855B0003B21 C?OpenDocument.

Australian Bureau of Statistics. (2020c). Weekly payroll jobs and wages in Australia, week ending 18 April 2020 (Cat. No. 6160.0.55.001). Australian Bureau of Statistics. Retrieved May 7, 2020, from https:// www.abs.gov.au/AUSSTATS/abs@.nsf/Lookup/6160.0.55.001Main+Features 1Week\%5C\% 20ending\%5C\%2018\%5C\%20April\%5C\% 202020?OpenDocument.

Australian Government Department of Health. (2020). New and cumulative COVID-19 cases in Australia by notification date [Australian Government Department of Health]. Retrieved April 26, 2020, from https://www.health.gov.au/resources/publications/new-and-cumulative-covid-19-cases-in-australia-bynotification-date.

Brantingham, P., \& Brantingham, P. (1993). Environment, routing and situation: toward a pattern theory of crime. In R. V. G. Clarke \& M. Felson (Eds.), Routine activity and rational choice. New Brunswick: Transaction Publishers.

Brantingham, P., \& Brantingham, P. (1995). Criminality of place: crime generators and crime attractors. European Journal on Criminal Policy and Research, 3(3), 5-26. https://doi.org/10.1007/BF02242925

Brooks, S. K., Webster, R. K., Smith, L. E., Woodland, L., Wessely, S., Greenberg, N., \& Rubin, G. J. (2020). The psychological impact of quarantine and how to reduce it: rapid review of the evidence. The Lancet, 395(10227), 912-920. https://doi.org/10.1016/S0140-6736(20)30460-8.

Campedelli, G. M., Aziani, A., \& Favarin, S. (2020). Exploring the effect of 2019-nCoV containment policies on crime: the case of Los Angeles. arXiv:2003.11021 [econ, q-fin, stat], arxiv 2003.11021. https://doi. org/10.31219/osf.io/gcpq8

Cohen, L. E., \& Felson, M. (1979). Social change and crime rate trends: a routine activity approach. American Sociological Review, 44(4), 588-608. https://doi.org/10.2307/2094589.

Davey, M. (2020). Victoria police respond to family violence risk during 'very stressful time' of coronavirus [The Guardian]. Retrieved April 27, 2020, from https://www.theguardian.com/australia-news/2020/apr/21 /victoria-police-respond-to-family-violence-risk-during-very-stressful-time-of-coronavirus?

Dowling, C., \& Morgan, A. (2016). Predicting repeat domestic violence: improving police risk assessment. Trends \& Issues in Crime and Criminal Justice, 581, 1-16.

Eisner, M., \& Nivette, A. (2020). Violence and the pandemic: urgent questions for research. New York: Harry Frank Guggenheim Foundation.

Elbogen, E. B., \& Johnson, S. C. (2009). The intricate link between violence and mental disorder: results from the National Epidemiologic Survey on Alcohol and Related Conditions. Archives of General Psychiatry, 66(2), 152-161. https://doi.org/10.1001/archgenpsychiatry.2008.537.

Europol. (2020). Catching the virus cybercrime, disinformation and the COVID-19 pandemic. European Union Agency for Law Enforcement Cooperation. The Hague, Netherlands. Retrieved April 25, 2020, from https://www.europol.europa.eu/publications-documents/catching-virus-cybercrime-disinformationand-covid-19-pandemic.

Farrell, G., \& Tilley, N. (2020). Coronavirus: how crime changes during a lockdown [The Conversation]. Retrieved April 25, 2020, from http://theconversation.com/coronavirus-how-crime-changes-during-alockdown-134948.

Fitz-Gibbon, K., \& Meyer, S. (2020). Coronavirus: fear of family violence spike as COVID-19 impact hits households [Lens: Pioneering research stories, commentary and opinion told by leading academicsMonash university]. Retrieved April 25, 2020, from https://lens.monash.edu/@ politics-society/2020/03/ 18/1379841?slug=coronavirus-fear-of- family-violence-spike-as-covid-19-impact-hits-households.

Foundation for Alcohol Research and Education. (2020). Many Australians using more alcohol and worried about household drinking [FARE]. Retrieved April 28, 2020, from https://fare.org.au/many-australiansusing-more-alcohol-and-worried-about-household-drinking/.

Freeman, K. (2020). Monitoring changes in domestic violence in the wake of COVID-19 social isolation measures. Crime and Justice Statistics Bureau Brief, 145, 4.

Gerell, M., Kardell, J., \& Kindgren, J. (2020). Minor COVID-19 association with crime in Sweden, a five week follow up. https://doi.org/10.31235/osf.io/w7gka 
Global Initiative Against Transnational Organized Crime (2020). Crime and contagion: The impact of a pandemic on organized crime. Geneva: Global Initiative Against Transnational Organized Crime.

Goodman, C. (2020). Mental health meltdown looms for South Florida, and coronavirus is the trigger. Retrieved April 29, 2020, from https:/www.sun-sentinel.com/coronavirus/fl-ne-mental-health-meltdown20200428-43wy4b6tu5ggfg4uymkwmwl5my-story.html.

Google. (2020). COVID-19 community mobility report [Google]. Retrieved April 27, 2020, from https://www. google.com/covid19/mobility.

Graham, K., Leonard, K. E., Room, R., Wild, T. C., Pihl, R. O., Bois, C., \& Single, E. (1998). Current directions in research on understanding and preventing intoxicated aggression. Addiction, 93(5), 659-676. https://doi.org/10.1046/j.1360-0443.1998.9356593.x.

Graham, K., Bernards, S., Wilsnack, S. C., \& Gmel, G. (2011). Alcohol may not cause partner violence but it seems to make it worse: a cross national comparison of the relationship between alcohol and severity of partner violence. Journal of Interpersonal Violence, 26(8),1503-1523. https://doi.org/10.1177 /0886260510370596.

Hulme, S., Morgan, A., \& Boxall, H. (2019). Domestic violence offenders, prior offending and reoffending in Australia. Trends \& Issues in Crime and Criminal Justice, 580, 1-22.

Jackson, A. (2020). A crisis mental-health hotline has seen an $891 \%$ spike in calls [CNN]. Retrieved April 10, 2020, from https://edition.cnn.com/2020/04/10/us/disaster-hotline-call-increase-wellness-trnd/index.html.

Kinner, S. A., Young, J. T., Snow, K., Southalan, L., Lopez-Acuña, D., Ferreira-Borges, C., \& O’Moore, É. (2020). Prisons and custodial settings are part of a comprehensive response to COVID-19. The Lancet Public Health, 5(4), e188-e189. https://doi.org/10.1016/S2468-2667(20)30058-X.

Lum, C., Maupin, C., \& Stoltz, M. (2020). The impact of COVID-19 on law enforcement agencies (wave 1). International Association of Chiefs of Police and the Center for Evidence- Based Crime Policy, George Mason University. Washington, D.C.

Midoes, C. (2020). Social distancing: did individuals act before governments? [Bruegel]. Retrieved April 25, 2020, from https://www.bruegel.org/2020/04/social-distancing-did-individuals-act-before-governments/.

Miller, P., Bruno, R., Morgan, A., Mayshak, R., Cox, E., Coomber, K., Droste, N., Taylor, N., Dimitrovski, N., Peacock, A., Boxall, H., \& Voce, I. (2016). Drug and alcohol intoxication and subsequent harm in night-time entertainment districts (DASHED) (Monograph Series No. 67). National Drug Law Enforcement Research Fund. Canberra.

Mohler, G., Bertozzi, A., Carter, J., Short, M., Sledge, D., Tita, G., Uchida, C., \& Brantingham, P. (2020). Impact of social distancing during COVID-19 pandemic on crime in Indianapolis.

Nivette, A., Ribeaud, D., Murray, A. L., Steinhoff, A., Bechtiger, L., Hepp, U., Shanahan, L., \& Eisner, M. (2020). Non-compliance with COVID-19-related public health measures among young adults: insights from a longitudinal cohort study. https://doi.org/10.31235/osf.io/8edbj.

Pearson, E. (2020). Family violence calls drop amid fears victims can't safely seek help while in lockdown [The Age]. Retrieved April 27, 2020, from https://www.theage.com.au/national/victoria/family-violencecalls-drop-amid-fears-victims-can-t-safely-seek-help-while-in-lockdown-20200401-p54fzq.html.

Peterman, A., Potts, A., O’Donnell, M., Thompson, K., Shah, N., Oertelt-Prigione, S., \& Van Gelder, N. (2020). Pandemics and violence against women and children (CGD Working Paper No. 528). Center for Global Development. Washington, DC. Retrieved April 27, 2020, from https://www.cgdev. org/publication/pandemics-and-violence-against-women-and-children.

Piquero, A. R., Riddell, J. R., Bishopp, S. A., Narvey, C., Reid, J. A., \& Piquero, N. L. (2020). Staying home, staying safe? A short-term analysis of COVID-19 on Dallas domestic violence. American Journal of Criminal Justice. https://doi.org/10.1007/s12103-020-09531-7.

Queensland Government. (2020). Queensland Offence rates-Open Data Portal [SBS]. Retrieved April 30, 2020, from https://www.data.qld.gov.au/dataset/offence-rates-monthly-from-july-1997.

Rossner, M., \& Tait, D. (2020). Courts are moving to video during coronavirus, but research shows it's hard to get a fair trial remotely [The Conversation]. Retrieved April 29, 2020, from http://theconversation. com/courts-are-moving-to-video-during-coronavirus-but-research-shows-its-hard-to-get-a-fair-trialremotely-134386.

Santhanam, L. (2020). Why child welfare experts fear a spike of abuse during COVID-19—PBS News Hour [PBS News Hour]. Retrieved June 30, 2020, from https:/www.pbs.org/newshour/health/why-childwelfare-experts-fear-a-spike-of-abuse-during-covid-19.

Shanahan, L., Steinhoff, A., Bechtiger, L., Murray, A. L., Nivette, A., Hepp, U., Ribeaud, D., \& Eisner, M. (2020). Emotional distress in young adults during the COVID-19 pandemic: evidence of risk and resilience from a longitudinal cohort study. Psychological Medicine, 1-32. https://doi.org/10.1017 /S003329172000241X. 
Shepherd, B. (2020). Coronavirus pressures see extra focus placed on family and domestic violence [ABC News]. Retrieved April 27, 2020, from https:/www.abc.net.au/news/2020-04-09/coronavirus-family-anddomestic-violence-fears-grow/12136652.

Talwar, R. (2020). Coronavirus lockdown: domestic violence complaints in Australia rise even as reports by phone fall [SBS]. Retrieved April 27, 2020, from https:/www.sbs.com.au/language/english/audio/coronaviruslockdown-domestic-violence-complaints-in-australia-rise-even-as-reports-by-phone-fall.

Tate, A. (2020). Domestic violence danger during coronavirus sparks urgent calls for cash [The New Daily]. Retrieved April 27, 2020, from https://thenewdaily.com.au/news/2020/04/21/coronavirus-lockdowndomestic-violence-help/

Ting, I., \& Palmer, A. (2020). One hundred days of the coronavirus crisis [ABC News]. Retrieved June 30, 2020, from https:/www.abc.net.au/news/2020-05-04/charting-100-days-of-the-coronavirus-crisis-inaustralia/12197884.

Tuohy, W. (2020). Helpline calls by family violence perpetrators 'skyrocket' amid isolation [The Age]. Retrieved April 27, 2020, from https:/www.theage.com.au/national/victoria/helpline-calls-by-familyviolence-perpetrators-skyrocket-amid-isolation-20200410-p54iw7.html.

Usher, K., Bhullar, N., Durkin, J., Gyamfi, N., \& Jackson, D. (2020). Family violence and COVID-19: Increased vulnerability and reduced options for support. International Journal of Mental Health Nursing. https://oi.org/10.1111/inm.12735.

van Gelder, N., Peterman, A., Potts, A., O’Donnell, M., Thompson, K., Shah, N., \& Oertelt-Prigione, M. S. (2020). COVID-19: Reducing the risk of infection might increase the risk of intimate partner violence. EClinicalMedicine. https://doi.org/10.1016/j.eclinm.2020.100348.

Voce, I., \& Boxall, H. (2018). Who reports domestic violence to police? A review of the evidence. Trends \& Issues in Crime and Criminal Justice, 559, 1-16.

Women's Safety NSW. (2020). New domestic violence survey shows impact of COVID-19 on the rise [Women's Safety NSW]. Retrieved April 27, 2020, from https://www.womenssafetynsw.org. $\mathrm{au} / \mathrm{impact} / \mathrm{article} / \mathrm{new}$-domestic-violence-survey-shows-impact-of-covid-19-on-the-rise/.

World Health Organization. (2020). WHO Director-General's statement on IHR Emergency Committee on Novel Coronavirus (2019- $n \mathrm{CoV})$ [World Health Organization]. Retrieved April 29, 2020, from https://www.who.int/dg/speeches/detail/who-director-general-s-statement-on-ihr-emergency-committeeon-novel-coronavirus-(2019-ncov).

Publisher's note Springer Nature remains neutral with regard to jurisdictional claims in published maps and institutional affiliations.

Jason L. Payne is Associate Professor of Criminology in the Research School of Social Sciences at the Australian National University, Canberra. He is also the Deputy-Associate Dean (Education) for the College of Arts and Social Sciences and Australian Capital Territory Representative to the Australian and New Zealand Society of Criminology. Jason has expertise in quantitative criminology, developmental and lifecourse criminology, and criminal justice drug policy.

Anthony Morgan is the Research Manager for the Australian Institute of Criminology's Serious and Organised Crime Research Laboratory. His research interests include the criminal careers of organised crime offenders and outlaw motorcycle gangs, policing responses to domestic violence, police use of technology and evidence-based crime prevention. He is a member of the Executive Committee for the Australia \& New Zealand Society of Evidence Based Policing.

Alex R. Piquero is Chair and Professor of the Department of Sociology and Arts \& Sciences Distinguished Scholar at the University of Miami and Professor of Criminology at Monash University in Melbourne Australia. He is also editor of Justice Evaluation Journal. His research interests include criminal careers, criminological theory, crime policy, evidence-based crime prevention, and quantitative research methods. He has received several research, teaching, and service awards, is fellow of both the American Society of Criminology and the Academy of Criminal Justice Sciences, and in 2019 he received the Academy of Criminal Justice Sciences Bruce Smith, Sr. Award for outstanding contributions to criminal justice. 